International Journal of Physical Sciences and Engineering
Available online at www.sciencescholar.us
Vol. 5 No. 1, April 2021, pages: $1-7$
ISSN: 2550-6951 E-ISSN: $2550-6943$
https://doi.org/10.29332/ijpse.v5n1.825

\title{
Computer Application for Studies of Potentials of Renewable Energy Sources
}

\author{
CrossMark \\ Juan Alejandro Martínez Linares ${ }^{1 *}$, Antonio Vázquez Pérez², Miguel Castro Fernández ${ }^{3}$, Miriam \\ Vilaragut Llanes ${ }^{4}$, Maria Rodríguez Gámez ${ }^{5}$
}

Manuscript submitted: 09 November 2020, Manuscript revised: 18 December 2020, Accepted for publication: 27 January 2021

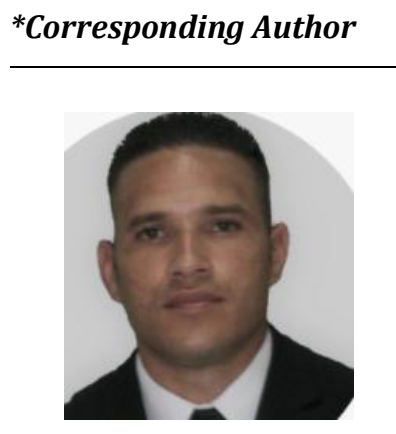

Keywords

geographical information

systems;

renewable energy

potentials;

renewable energy

sources;

territorial energy

ordination;

\begin{abstract}
Computer science's technologies have come to revolutionize the current era, the distributed generation and the introduction of new alternatives in the conception of the energy production, it is a factor that seen from the energy planning it allows to introduce the renewable energy sources as an element in the development of energetically sustainable territories. The space distribution of the natural resources that they generate, it has made necessary to develop advanced systems for the studies at the space level. For the necessities of printing an analysis space and territorial of the renewable energy sources studies, a geographical information system of renewable energy sources was designed using free software that offers information of the renewable potentials in the territory. This system is a tool that allows an appropriate way to offers information of the place (longitude and latitude) and the potentials (solar, hydric, wind, and biomass) that are generated in them.
\end{abstract}

\section{Contents}

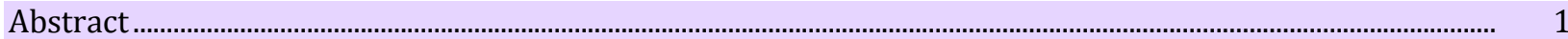

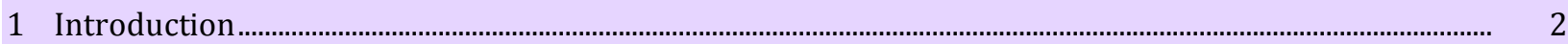

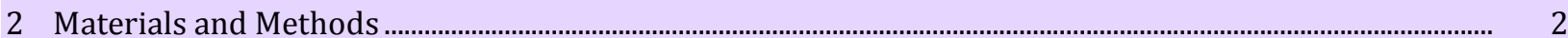

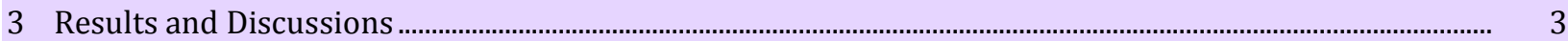

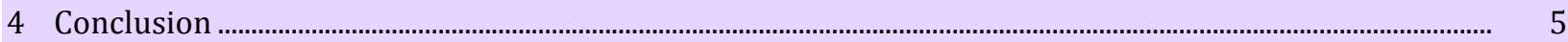

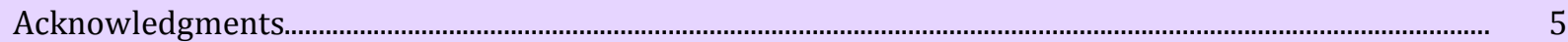

\footnotetext{
${ }^{1}$ Sistemas Informáticos y electrónicos del Este S.A, San José, Costa Rica

${ }^{2}$ Universidad Técnica de Manabí, Carrera de Ingeniería Industrial, Portoviejo, Manabí, Ecuador

${ }^{3}$ Universidad Tecnológica de La Habana, Centro de Investigaciones y Pruebas Electroenergéticas (Cujae)La Habana, Cuba

${ }^{4}$ Universidad Tecnológica de La Habana, Centro de Investigaciones y Pruebas Electroenergéticas (Cujae)La Habana, Cuba

${ }^{5}$ Universidad Técnica de Manabí, Carrera de Ingeniería Eléctrica, Portoviejo, Manabí, Ecuador
} 


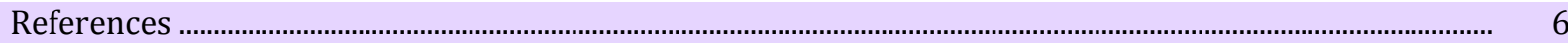

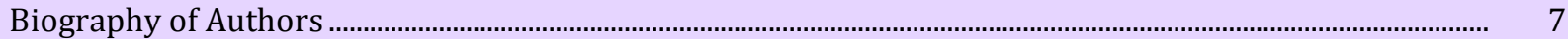

\section{Introduction}

At present, websites and Geographic Information Systems (GIS) are conceived as an application on different fronts, since they are instruments that allow companies and decision-makers to help the real knowledge of the space where social relationships take place and their interaction with the environment. Geographical Information Technologies are considered part of the central nucleus of Geography since geographers have a prominent role in its development, are part of the main conceptual traditions of the subject, and have a marked professional projection (Chuvieco et al., 2005; Kingston et al., 2000; Nath et al., 2000).

The Geographical Information System of Renewable Energy Sources (SIGFRE) in Cuba is a tool that in energy applications has gone through various scenarios and levels of development, in a first stage it was designed for a municipality in the inventory of communities and settlements that were not electrified (Dominguez \& Amador, 2007), this technology was passing through to provincial studies, its fundamental application was carried out in the province of Santiago de Cuba (Gámez, 2011) and taking into account the results obtained were used in the energy planning of said territory (Rodríguez et al., 2017). The application of the system has been developed and expanded to new provinces that are incorporated into the database (DB), between 1998 and 2002 it was generalized to the five eastern provinces (Holguín, Granma, Guantánamo, Las Tunas, and Santiago de Cuba), mainly for inventories and knowledge of the communities without electrification, as well as the study of the type of existing electrification (Martin et al., 2016).

To achieve that the application could be introduced, in such a way that it offered information and that it could also be updated, made reports, printed, etc. A variant was developed that in its beginnings was capable of managing the potentials in the territory, providing information for the pre-investment stage, being able to carry out the macro localization starting from the inventories of potentials of renewable energy sources (FRE) and of the elements of space that influence and are related to achieve the ordering of energies in the territory, but this system had to be user-friendly and easy to manipulate (Wirba et al., 2015; Shaaban \& Petinrin, 2014).

To meet these expectations, it was essential to go through a stage, in which the requirements that would lay the foundations of the potential of the FRE in the application to be implemented were compiled. Therefore, based on the domain model obtained, and to establish the second module as the main element of SIGFRE, from determining the functionalities that it will have, to guide the development towards obtaining a design that meets the client's required expectations and that can be used throughout the country for the study and territorial energy planning during the pre-investment stage as part of the decision-making process in the introduction of the FRE, based on the concepts that the reality of the energy space can be known, which includes the satisfaction of demand in the population centers with the highest consumption (Belmonte et al., 2009; Pomares et al., 2020).

\section{Materials and Methods}

The base created at the country level was used as a starting point, based on the existing politicaladministrative division. For the design of the base maps to be used, cartography 1:250000 and 1: 100000 was used. For the potential maps, information was taken from different sources: the solar and wind potential were developed with data published on the SWERA website; the hydraulic potential map was prepared with the existing cartography up to the level of dams and rivers, and alphanumerical information provided by the company Hydro energy; The biomass potentials being so diverse, different types of information were used in cartography 1: 100000 for the maps of the country, where the soils occupied by sugarcane, coffee, marabou, rice, forests were inventoried; The biomass for the generation of biogas was obtained with the inventories of the industries that in their processes generate considerable amounts of organic waste, in addition to the inventory of the facilities where concentrates, pigs, poultry, cattle, and goats, etc. are found was used software Free downloaded from the internet with the objective of the system that is designed to be multiplied and 
achieve the expected results regarding their use and enrichment of the database of the potential of FRE and applications technologies that take advantage of these sources.

\section{Results and Discussions}

With some frequency, the image of the territory held by specialists and some decision-makers in the energy sector does not exactly match the geographic reality or the relationships established therein. The territorial imprint of the implementation of renewable energy sources, as well as the incorporation of economic concepts in their application and use, makes it necessary to reconcile the intervention, regulation, and integration criteria within the energy organization (Koutroulis \& Kalaitzakis, 2003; Kothari et al., 2010).

Until the moment that SIGFRE is conceived, the extraordinary volume of information that exists on the inventory and the potentials of renewable energy sources is scattered in the profile of the institutions and organizations that have the responsibility of controlling their development, is so for example: that there is a National Photovoltaic Solar Energy Group; another for solar thermal energy; a group for wind energy; for hydraulics; and in the case of bioenergy, it is subdivided by types, as well as others that, when not directly related to its use, have to do with its use, such as the Energy Accumulation Group.

From the institutional point of view, the Electricity Union has the Emergency Directorate which, among its functions, takes care of the development and management of wind farms, existing hydroelectric plants of different powers, and photovoltaic plants connected to the grid; but the windmills that use wind energy are partially served by the Ministry of Agriculture and the autonomous photovoltaic systems are served by COPEXTEL. In this way, issues related to the development of renewable sources are scattered in various state and government institutions.

In this scenario, it is difficult to be able to establish an analysis on energy management that may have an integrative character, where it is possible to evaluate the availability of the different energy sources, to have an idea of which of them is more economical and of better environmental impacts or social, being able to make a decision adjusted to the introduction of the variant that is more profitable and safer for the investment. In any case, if you want to evaluate this nature, it is necessary to invest time and resources in information, meetings, trips, consultations, and other activities that are not always possible to achieve due to space, time, and availability of material and economic resources (Rodríguez et al., 2013). The foregoing can be corroborated by the results of the report with the guide to recommendations for the use of renewable energies in rural electrification, presented in July 2002 by the Japan International Technical Cooperation Agency (JICA), with the cooperation of the Solar Energy Research Center (CIES) and the Priority Programs and Projects Management Center (GEPROP), both of the Ministry of Science, Technology, and Environment (CITMA) of the Government of Cuba.

SIGFRE manages to link in a single site all the required information, to be able to carry out comprehensive analyzes and evaluations on the intervention opportunities of each energy source in the development plans of the country and territories. The information can be accessed from anywhere and related to any site in the national territory, with the incorporation of geo referenced graphic attributes, capable of providing a greater spectrum of local informative references. Information systems are useful for energy planning (Pistonesi et al., 2019), the Economic Commission for Latin America and the Caribbean (CEPAL) has investigated the state of regional energy planning and the challenges in integrating renewable energy to achieve sustainable planning that allows regional energy integration.

\section{The argumentation of the tools, languages, and technologies to be used}

Prado version 3.1.7 has been used as a php framework, to make the manipulation of each application module feasible, in a simple way and with the minimum of possible errors, since it is a well-defined conceptual and technological support structure, usually with artifacts or specific software modules, based on which our project can be organized and developed. PRADO is a PHP framework or programming layer based on components and event programming, for the implementation of Web applications in PHP 5, PRADO (PHP Rapid Application Development Object-oriented) which means in Spanish rapid development of applications with programming oriented to objects in PHP (EcuRed).

Linares, J. A. M., Pérez, A. V., Fernández, M. C., Llanes, M. V., \& Gámez, M. R. (2021). Computer application for studies of potentials of renewable energy sources. International Journal of Physical Sciences and Engineering, 
Geoserver is an open-source server written in Java, which allows users to share and edit geospatial data. It has been designed from the beginning to work under interoperability standards. It is capable of publishing services from the main data sources using open standards (www.zonageo.com.ar, 2012c). Version 2.3.2 has been used as a geospatial data server, that is, a map server and its data, which allows users to consult and edit data throughout the project.

PostgreSQL is a free software object-oriented relational database management system (DBMS), released under the BSD license. Like many other projects open source, PostgreSQL development is not managed by a single company but is led by a community of developers and commercial organizations, who work on its development. This community is called the PostgreSQL Global Development Group (PGDG) (www.zonageo.com.ar, 2012f).

During the design of the project, it was estimated to use PostgreSQL version 9.1 as DBMS, where all the geospatial data with which the system will work will be stored. PostGIS is a module that adds support for geographic objects to the PostgreSQL object-relational database, turning it into a spatial database for use in the Geographic Information System. It is published under the GNU Project General Public License (www.zonageo.com.ar, 2012e).

PostGIS version 1.5.2-3 was applied as a link between the map server and the database server, as it adds support for geographic objects to the PostgreSQL database and implements spatial extensions based on the specifications of the Open Geospatial Consortium (OGC). ExtJS is a JavaScript library for developing interactive web applications using technologies such as AJAX, DHTML, and DOM. Originally built as an extension to the YUI library, it can now be used as an extension to the JQuery and Prototype libraries. Since version 1.1 it can be run as an independent application (www.zonageo.com.ar, 2012a).

The JavaScript library called ExtJS version 3.4.0, is applied to improve interaction with the user since it offers the ability to provide components with advanced functionalities and easy implementation. It's about being easy to use and intuitive. The library is applied GeoExt, which constitutes a tool used for the construction of web map applications based on JavaScript (www.zonageo.com.ar, 2012b). In this case, GeoExt version 1.1 is used, which is a tool built from the robust OpenLayers library and the rich graphic components of ExtJS. It has components for GIS applications, allowing you to create powerful JavaScript-based map websites.

OpenLayers is a JavaScript library (provided from a modified BSD license) to view maps and other geographic data in a Web browser. It includes an API to build rich applications similar to GoogleMaps (Google, 2005). The library includes components from the Rico and Prototype library (www.zonageo.com.ar, 2012d). Specifically for the project, OpenLayers version 2.12 is used to facilitate the management of maps on the client-side. In figure 1 can be seen the relationship scheme of the different technologies used for the development of SIGFRE.

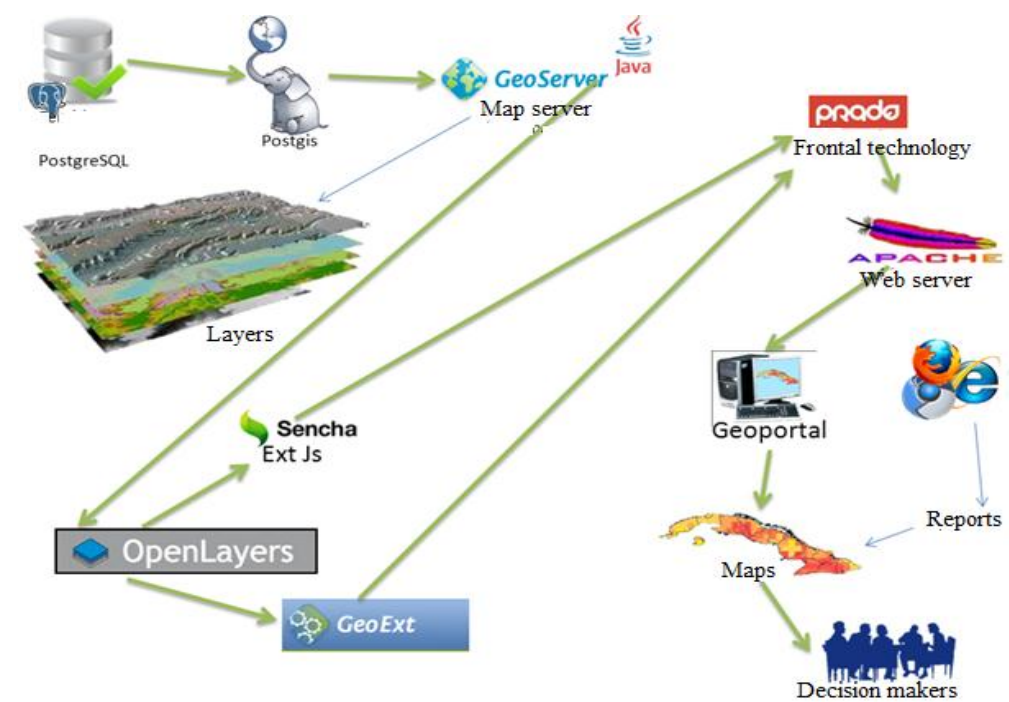

Figure 1. Relationship diagram between the different technologies used for the development of SIGFRE 


\section{Presentation of the application}

The application is prepared to be operated by users in an intuitive, simple and friendly way, that is, without having specialized computer knowledge, consultation actions can be carried out and in some cases updates in the different modules for which it is found. conceived the system. The opening of the system has been conceived through a web page with various information on the FRE and through the hyperlinks in the menu, access is made to the different sub-modules related to the information in the registry. In figure 2 shows the sub-module of the solar potential. In this case, if you want to know the characteristics of the solar radiation of a site, just by clicking on the location on the map, the information is displayed by months and the annual average of the potential itself.

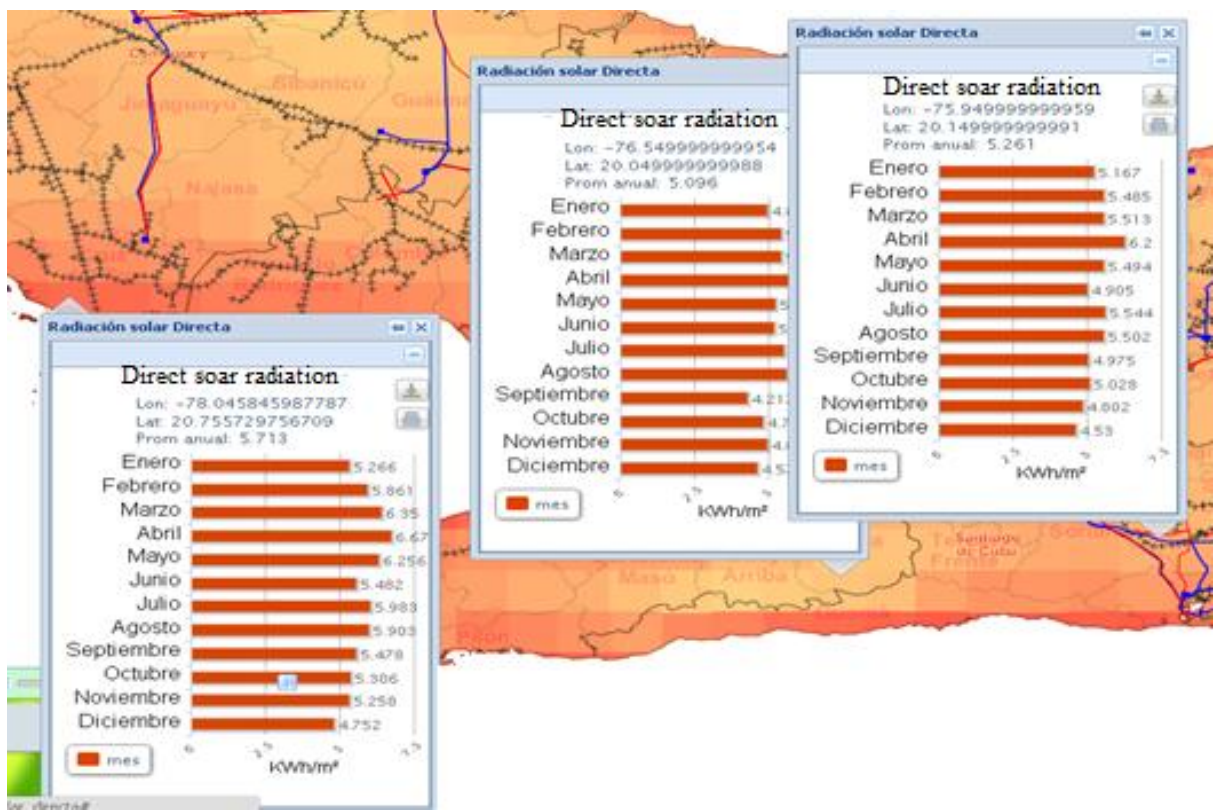

Figure 2. Solar potential seconds after the user has requested it from SIGFRE

This system offers information on direct solar radiation anywhere in the country that is clicked, being able to know the solar potential that affects to carry out energetic studies from fluid heating to power generation.

\section{Conclusion}

SIGFRE is capable of offering reliable, integrated, and timely georeferenced information on RES inventories and potentials, making available to users a useful tool with which to interact to ensure the adequate use of the energy resources that exist at the level of the localities, with the capacity to fill an information gap that in an inclusive nature offers and facilitates access to multiple sustainable energy applications for the territories. The system has the potential to be used by users identified at the different levels of the country's political and administrative system, being able to help in the short, medium, and long term territorial energy planning process, helping to develop the use of renewable sources and the development of territories.

\section{Acknowledgments}

The authors thank the Centro de Investigaciones y Pruebas Electroenergéticas (CIPEL), management for supporting the research carried out.

Linares, J. A. M., Pérez, A. V., Fernández, M. C., Llanes, M. V., \& Gámez, M. R. (2021). Computer application for studies of potentials of renewable energy sources. International Journal of Physical Sciences and Engineering, 5(1), 1-7. https://doi.org/10.29332/ijpse.v5n1.825 


\section{References}

Belmonte, S., Núñez, V., Viramonte, J. G., \& Franco, J. (2009). Potential renewable energy resources of the Lerma Valley, Salta, Argentina for its strategic territorial planning. Renewable and Sustainable Energy Reviews, 13(6-7), 1475-1484. https://doi.org/10.1016/j.rser.2008.09.014

Chuvieco, E., Sendra, JB, Fernández, XP, García, CC, Preciado, JMS, Puebla, JG, ... \& Velasco, MJP (2005). Are Geographic Information Technologies (GIT) part of the core of Geography? Bulletin of the Association of Spanish Geographers.

Domínguez, J., \& Amador, J. (2007). Geographical information systems applied in the field of renewable energy sources. Computers \& Industrial Engineering, 52(3), 322-326. https://doi.org/10.1016/j.cie.2006.12.008

Gámez, MR (2011). The management and planning of renewable energy sources on the island of Cuba from a territorial perspective. Case study in the municipality of Guama from a geoportal (Doctoral dissertation, Pablo de Olavide University).

Kingston, R., Carver, S., Evans, A., \& Turton, I. (2000). Web-based public participation geographical information systems: an aid to local environmental decision-making. Computers, environment and urban systems, 24(2), 109-125. https://doi.org/10.1016/S0198-9715(99)00049-6

Kothari, R., Tyagi, V. V., \& Pathak, A. (2010). Waste-to-energy: A way from renewable energy sources to sustainable development. Renewable and Sustainable Energy Reviews, 14(9), 3164-3170. https://doi.org/10.1016/j.rser.2010.05.005

Koutroulis, E., \& Kalaitzakis, K. (2003). Development of an integrated data-acquisition system for renewable energy sources systems monitoring. Renewable Energy, 28(1), 139-152. https://doi.org/10.1016/S09601481(01)00197-5

Martín, Ana María., Domínguez, Javier \& Guerra, Julio (2016). Geofocus: Revista Internacional de Ciencia y Tecnología de la Información Geográfica, ISSN-e 1578-5157, №. 18.

Nath, S. S., Bolte, J. P., Ross, L. G., \& Aguilar-Manjarrez, J. (2000). Applications of geographical information systems (GIS) for spatial decision support in aquaculture. Aquacultural Engineering, 23(1-3), 233-278. https://doi.org/10.1016/S0144-8609(00)00051-0

Pistonesi, H., Bravo, G., \& Contreras Lisperguer, R. (2019). Situational mapping of regional energy planning and challenges in the integration of renewable energies: towards sustainable planning for regional energy integration.

Pomares, L. F., Pérez, A. V., \& Gámez, M. R. (2020). The pinar del río geography and connected photovoltaic systems to grid. International Research Journal of Management, IT and Social Sciences, 7(3), 1-10.

Rodríguez Gámez, M., Vázquez Pérez, A., Castro Fernández, M., \& Vilaragut Llanes, M. (2013). Photovoltaic systems and land use planning. Energy Engineering, 34 (3), 247-259.

Rodríguez, M., Vázquez, A., Saltos, M. Revistas Yuyaricuna Núm. XVI (2017), XVI Conferencia de Sistemas de Información Geográfica.

Shaaban, M., \& Petinrin, J. O. (2014). Renewable energy potentials in Nigeria: Meeting rural energy needs. Renewable and Sustainable Energy Reviews, 29, 72-84. https://doi.org/10.1016/j.rser.2013.08.078

Wirba, A. V., Mas' ud, A. A., Muhammad-Sukki, F., Ahmad, S., Tahar, R. M., Rahim, R. A., ... \& Karim, M. E. (2015). Renewable energy potentials in Cameroon: Prospects and challenges. Renewable energy, 76, 560-565. https://doi.org/10.1016/j.renene.2014.11.083 


\section{Biography of Authors}

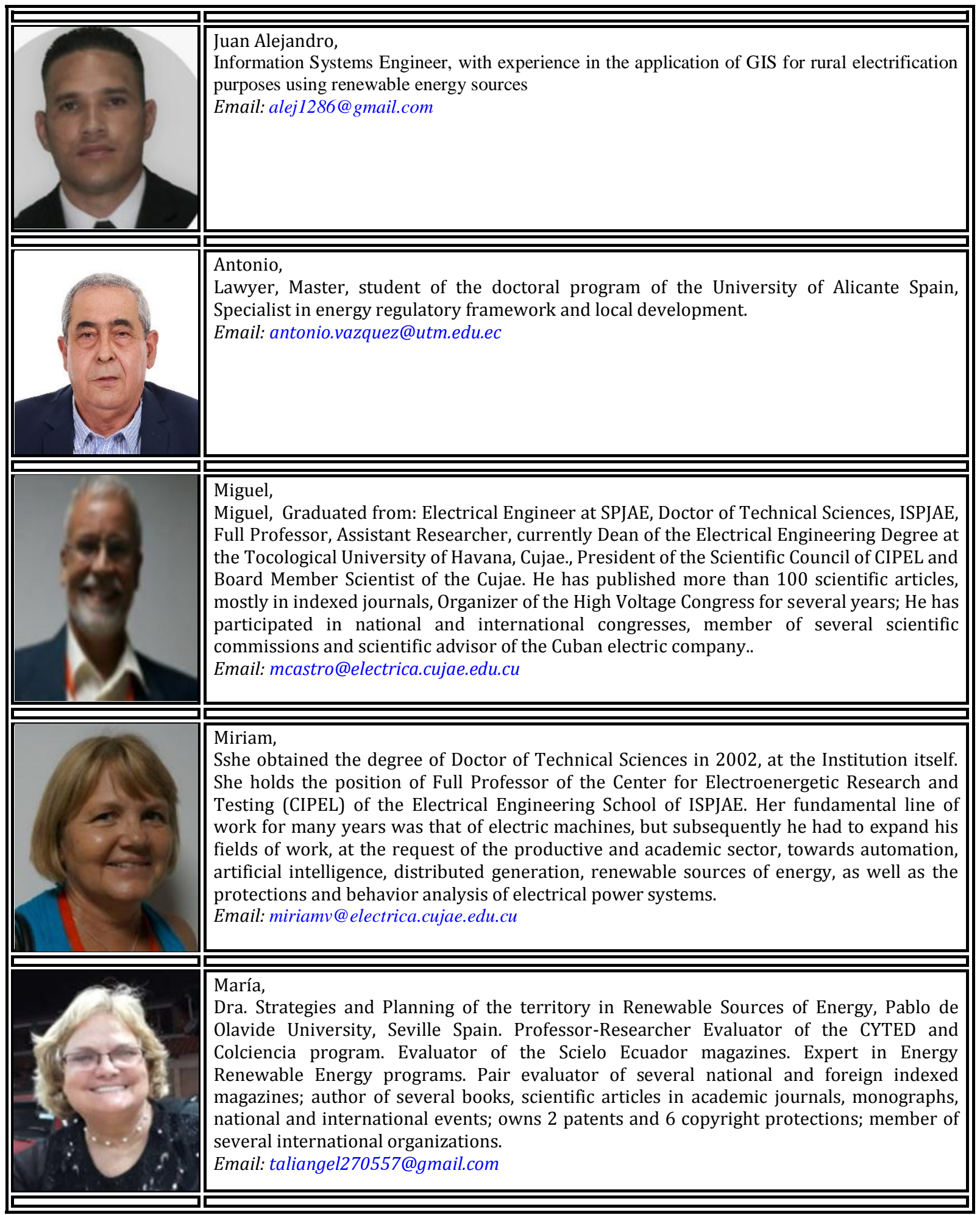

Linares, J. A. M., Pérez, A. V., Fernández, M. C., Llanes, M. V., \& Gámez, M. R. (2021). Computer application for studies of potentials of renewable energy sources. International Journal of Physical Sciences and Engineering, 5(1), 1-7. https://doi.org/10.29332/ijpse.v5n1.825 